\title{
Scour of Chinook Salmon Redds on Suction Dredge Tailings
}

\author{
Bret C. HarveY* and Thomas E. Lisle \\ Pacific Southwest Research Station, U.S. Forest Service, \\ I700 Bayview Drive, Arcata, California 95521, USA
}

\begin{abstract}
We measured scour of the redds of chinook salmon Oncorhynchus tshawytcha on dredge tailings and natural substrates in three tributaries of the Klamath River, California. We measured maximum scour with scour chains and net scour by surveying before and after high winter flows. Scour of chinook salmon redds located on dredge tailings exceeded scour of redds on natural substrates, although the difference varied among streams. Our results show that fisheries managers should consider the potential negative effects of dredge tailings on the spawning success of fali-spawning fishes such as chinook salmon and coho salmon 0 . kisutch.
\end{abstract}

Suction dredging for gold is common in many streams and rivers in western North America and in gold-bearing lotic habitats worldwide (Hall 1988). Studies of the effects of dredging on fishes have focused on survival following entrainment (Griffith and Andrews 1981) or the immediate responses of fishes to changes in habitat caused by dredging (Harvey 1986). The effect of suction gold dredging on fish spawning has not been studied, in part because dredging rarely overlaps in time with spawning by species of special concern to fisheries managers. Also, in many unregulated streams, most fishes spawn in spring after dredge tailings from the previous summer and fall are redistributed by high winter flows (Thomas 1985; Harvey 1986).

However, dredging during summer may affect the reproductive success of fall-spawning fishes such as chinook salmon Oncorhynchus tshawytscha. Because of low streamflow during late summer and early fall, dredge tailings may retain their original form during the spawning period of these species. Tailings often contain substrate appropriate for redd construction and may be used by fallspawning salmonids. The significance of dredge tailings to fish populations depends in part on the extent dredge tailings are used for spawning, which is itself probably affected by the availability of suitable unaltered substrates and the relative quality of dredge tailings as spawning sites. Because dredge tailings may be more unstable than

* Corresponding author: bch3@axe.humboldt.edu

Received June 24, 1998

Accepted October 6, 1998 natural substrates, redds on tailings may be subject to greater scour than those on unaltered substrates. Greater scour of tailings would significantly decrease their quality as spawning sites because mortality of preemergent salmonids can be sensitive to small increases in scour depth (Holtby and Healey 1986; Montgomery et al. 1996). Our objective in this study was to test the null hypothesis that chinook salmon redds on dredge tailings and those on natural substrates are scoured equally.

\section{M ethods}

Study sites.-We made scour measurements in three tributaries of the Klamath River in Siskiyou County, northwestern California: Elk Creek, the South Fork Salmon River, and the Scott River (Table 1). Regional streamflow is highly seasonal; most peak flows result from rainfall or rain-onsnow events during wet winters. Suction dredging occurs from June to September. Spawning by chinook salmon occurs most often in October and November, and storm flows capable of mobilizing streambed material typically occur from December to March. All study reaches are single-thread, slightly sinuous alluvial channels with limited floodplains bounded by valley walls. Bed surfaces are predominated by cobbles and boulders. Scour and fill of the streambeds can be expected to vary annually because, although these channels have high sediment supplies typical of the Klamath Mountains, winter streamflow is highly variable. Scour and fill also can be expected to vary spatially because patches of gravel are transported annually whereas boulders move less frequently.

Measurement of scour.-We measured maximum and net scour of redds on dredge tailings and on natural substrate. We directly measured maximum scour at each redd with two scour chains positioned on either side of the redd where bed elevation approximately equaled the surrounding substrate, about midway along the longitudinal axis of the tailspill. We chose these chain locations to avoid damaging embryos and to measure local scour depths presumably equal to those at the bracketed redds. We inserted scour chains in October and November, before large increases in stream discharge obscured the locations of redds 
TABLE 1.-Characteristics of the three study sites, including estimated recurrence intervals for peak flows during the study based on nearby gauging stations at Scott River near Ft. Jones, South Fork Salmon River near Somes Bar, and Indian Creek near Happy Camp for Elk Creek (peak flows in Indian Creek from 1955 to 1964 predicted peak flows in Elk Creek with $\left.r^{2}=0.81\right)$.

\begin{tabular}{lccccc}
\hline \multicolumn{1}{c}{ Stream } & Years of study & $\begin{array}{c}\text { Drainage } \\
\text { area }\left(\mathrm{km}^{2}\right)\end{array}$ & $\begin{array}{c}\text { Width } \\
(\mathrm{m})\end{array}$ & $\begin{array}{c}\text { Gradient } \\
(\%)\end{array}$ & $\begin{array}{c}\text { Peak-flow } \\
\text { recurrence } \\
\text { interval } \\
\text { (years) }\end{array}$ \\
\hline Elk & $1993-1994$ & 234 & 19 & 1.4 & 0.3 \\
& $1994-1995$ & & & & 2.0 \\
Scott & $1995-1996$ & 2,055 & 29 & 0.6 & 1.1 \\
South Fork Salmon & $1995-1996$ & 712 & 22 & 1.0 & 1.1 \\
\hline
\end{tabular}

and returned to measure scour in June or July of the following year. Scour chains measure the maximum scour depth that may be followed by some thickness of fill during the measurement period (Leopold et al. 1964; Nawa and Frissell 1993). Net scour is the difference in streambed elevation between the start and end of the measurement period (assuming elevation decreases). We measured net scour by first surveying longitudinal profiles and monumented cross sections over the redds when scour chains were installed in the fall and then resurveying them the following summer when chains were recovered.

Replication ranged from three to seven within a particular combination of stream, year, and substrate (tailings versus natural substrate). In general, replication was limited by the number of redds on tailings. We readily detected redds on natural substrates because less periphyton covered redd materials compared with the surrounding substrate. This difference was less apparent for redds on recently created dredge tailings, and low stability of material in tailings often yielded redds with less strongly mounded tailspills compared with those on natural substrates. For these reasons, redds on tailings were often difficult to identify in the absence of direct observations of spawning fish. After locating as many redds on tailings as possible, we haphazardly selected an equal number of redds on natural substrates by making measurements at the first redds we encountered either upstream or downstream of the redds on dredge tailings.

Analysis.-We analyzed net scour using a twoway analysis of variance (ANOVA) with site and substrate (tailings versus natural substrates) as main effects. Our four sets of observations for particular streams in a specific year constituted the sites. Although the site factor contains indistinguishable variation due to annual variation and geographic location, we think analysis of data from three streams collected over 3 years provides a reasonable first assessment of scour on dredge tailings versus natural substrates.

We analyzed the scour-chain data using the same two-way ANOVA approach. However, the data set was reduced for this analysis because scour chains were not recovered at all the redds surveyed. Because we suspected that some unrecovered scour chains were removed by people rather than by scour in excess of the depth of the chains, only redds where at least one scour chain was recovered were included. For 3 of the 26 observations included in this analysis, only one scour chain was recovered. For these observations we averaged the depth of scour at the chain recovered with the burial depth of the lost chain to produce a conservative estimate of maximum scour. Overall, this analysis provides a conservative estimate of differences in scour on dredge tailings versus natural substrates because sites with extreme scour, where scour chains were lost because they were completely exhumed, were excluded from the data set.

\section{Results}

Topographic changes at redds following high winter flows ranged from extensive scour and fill to nearly undetectable differences (Figure 1). Net and maximum scour of chinook salmon redds on dredge tailings were significantly greater than

Figure 1.-Examples of changes in cross sections and longitudinal profiles at two redd sites. Scour and fill were deep at the Elk Creek site, and the two scour chains (not shown) were lost. Net scour was less at the Scott River site, and scour chains recorded a maximum scour approximately $10 \mathrm{~cm}$ below the final bed elevation. Elevations were surveyed relative to an arbitrary data point. 
Elk Creek Dredge Site \#2

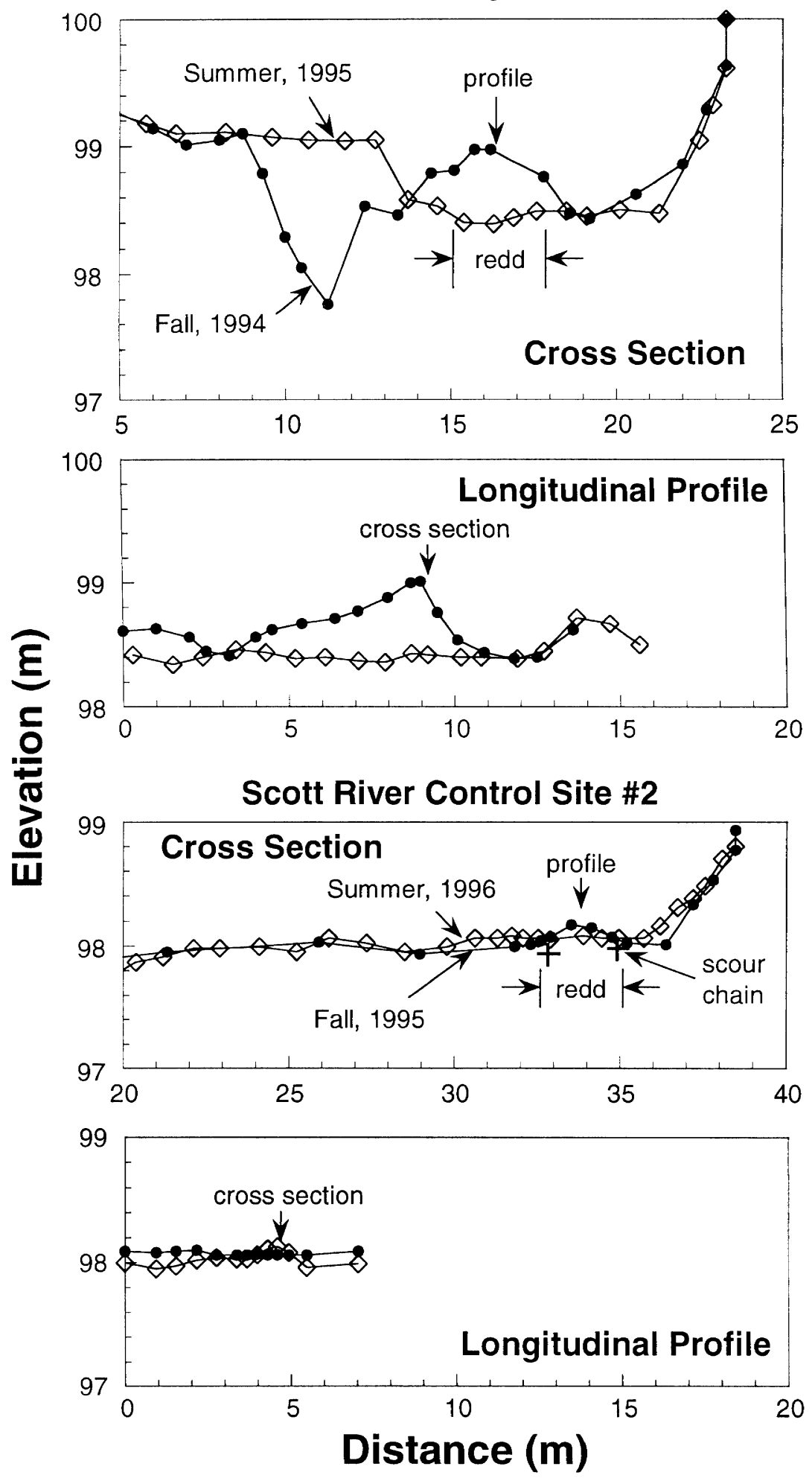




\section{Elk 94 Elk 95 Salmon Scott}
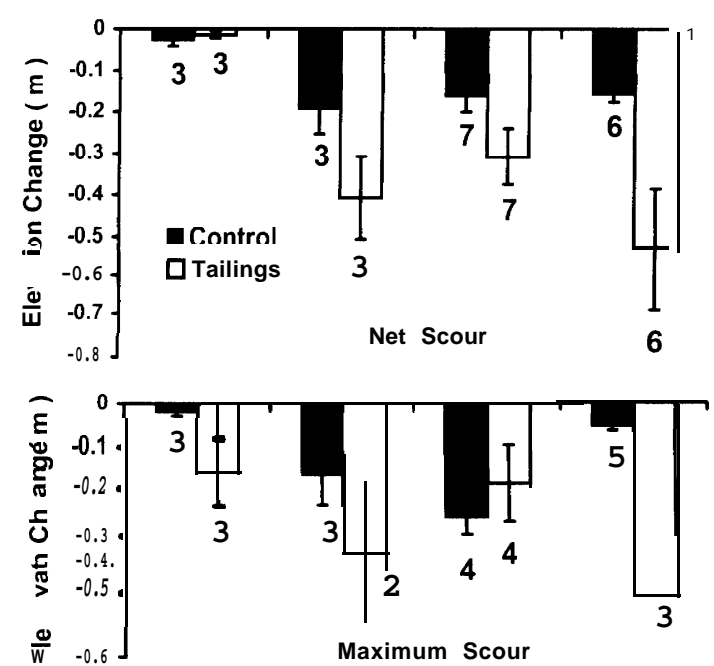

FIgURE 2.-Elevation change over winter at chinook salmon redds located on dredge tailings and on natural substrates (control) in tributaries of the Klamath River, 1993-1996. Net scour data reflect the elevation change at the middle of the tailspill, whereas maximum scour data indicate the average scour estimated at two scour chains positioned on either side of the longitudinal midpoint of the tailspill at about the elevation of the surrounding natural substrate. Estimates of net scour can exceed maximum scour because scour chains were not recovered at all redds. Error bars $= \pm \mathrm{SE}$; numbers below the bars indicate sample size.

scour of redds on natural substrates (for survey data: $F=7.88$, df $=1,30, P<0.01$; for scourchain data: $F=8.85$, df $=1,17, P<0.01$ ), but differences varied among sites (substrate $X$ site interaction for survey data: $F=2.60$, df $=3,30$, $P=0.07$; for scour-chain data: $F=3.27, \mathrm{df}=3$, $17, P<0.05$; Figure 2). Variation among our four sets of observations can be attributed, in part, to annual variation in discharge. For example, in Elk Creek, low winter streamflow in 1993-1994 (Table 1) caused little scour compared with 1994-1995 (Figure 2).

Net and maximum scour were strongly correlated $(r=0.75, \quad P<0.01)$ for the 25 redds where we recovered one or more scour chains. Fill following maximum scour will weaken the correlation between these two measurements; outliers in our data occurred where maximum scour greatly exceeded net scour. In most cases, net and maximum scour were approximately equal, indicating that filling did not occur after scour. This suggests that meaningful measurements of scour of redds in mobile material can be made by surveying only.

\section{D iscussion}

Previous observations suggest that the greater scour we observed at redds on dredge tailings than on natural substrates had significant consequences for the survival of chinook salmon eggs and embryos. For example, Holtby and Healey (1986) observed a strong correlation between mortality of young-of-the-year coho salmon 0 . kisutch and peak discharge during the incubation period. Montgomery et al. (1996) measured both scour and egg pocket burial depths of chum salmon 0. keta in a Washington stream and determined that a small increase in scour would affect the integrity of a large proportion of redds. Based on previous studies, DeVries (1997) suggested that loss of eggs from chinook salmon redds will begin when scour reaches $15 \mathrm{~cm}$ below the original streambed elevation and scour of $50 \mathrm{~cm}$ will cause total loss of eggs. These estimates and the differences in scour we observed suggest that many more preemergent chinook salmon were lost from redds on dredge tailings compared with redds on natural substrates. However, our results also revealed that variability in scour between dredge tailings and natural substrates should be expected among streams and years.

The significance of dredge tailings to salmon populations may vary even among streams with similar patterns of scour. The proportion of chinook salmon that spawn on dredge tailings would influence the population level effect of tailings and depend, in part, on the availability of spawning sites on natural substrates. If natural spawning sites were relatively abundant and tailings were not strongly selected, a small fraction of redds would be located on tailings. For example, in the lower $11 \mathrm{~km}$ of the Scott River in 1995, only 12 of 372 redds were located on tailings (J. Kilgore, U.S. Forest Service, unpublished data) because (1) much more natural substrate than dredge tailings provided spawning habitat (an estimated $3,890 \mathrm{~m}^{2}$ versus $121 \mathrm{~m}^{2}$ ), and (2) the fish exhibited no strong preference for either substrate $\left(0.09 \mathrm{redds} / \mathrm{m}^{2}\right.$ for natural substrate versus $0.10 \mathrm{redds} / \mathrm{m}^{2}$ for dredge tailings). However, where natural spawning substrate is in short supply, a large proportion of redds may be located on dredge tailings.

Both the timing of spawning and the body size of spawners will also affect the significance of dredge tailings on spawning success. Because peak seasonal discharge in the streams we studied commonly occurs in December and January, the period of maximum scour usually overlaps with the em- 
bryo incubation period of chinook salmon and coho salmon. Steelhead Oncorhynchus mykiss are probably less affected by scour because they spawn later, after tailings are likely to be redistributed by high flows and when high flows during incubation are less likely. Fish able to deeply bury eggs should be favored where scour is significant (Holtby and Healey 1986). Both within and among species, larger females usually bury eggs deeper (van den Berghe and Gross 1984; Crisp and Carling 1989).

Applying typical values for depth of scour and egg burial in undisturbed substrates to the dredging situation can be misleading. Miners commonly deposit gravelly material over much coarser armor layers of cobbles and boulders; these areas are often hydraulically suitable for spawning, but do not have appropriate substrate. Thus, unlike redds on undisturbed substrates, redds on dredge tailings are constructed on an anomalously fine bed surface, and fish may be impeded from digging and depositing eggs into the original armor layer because of its coarseness. Therefore, fish may deposit their eggs in the overlying finer gravel that is vulnerable to strong scouring forces. In such cases, scour during a common peak flow would often extend down to the depth of the original armor layer and would include the layer containing incubating embryos.

Our results show that fisheries managers should consider the potential negative effects of dredge tailings on the spawning success of fall-spawning fish, such as chinook salmon and coho salmon. Streams with a shortage of natural substrate appropriate for spawning, a high potential for scour, and a low number of spawners deserve special attention. Where managers determine that unstable dredge tailings may lead to unacceptable effects on spawning success, these effects could be reduced or eliminated through regulations that require that tailings piles be redistributed to restore the original bed topography and particle size distribution.

\section{Acknowledgments}

Sue Hilton, Nels Brownell, and Jim Kilgore headed field crews for this study. Sue Hilton de- ciphered and compiled the field notes. Fran Janemark, Jim Kilgore, and Brenda Olson identified possible study sites. We thank these people and those who assisted in the field. This research was supported in part by the U.S. Forest Service Region 5 Fish-Habitat Relationships Program.

\section{References}

Crisp, D. T., and P. A. Carling. 1989. Observations on siting, dimensions and structure of salmonid redds. Journal of Fish Biology 34:119-134.

DeVries, P. 1997. Riverine salmonid egg burial depths: review of published data and implications for scour studies. Canadian Journal of Fisheries and Aquatic Sciences 54:1685-1698.

Griffith, J. S., and D. A. Andrews. 1981. Effects of a small suction dredge on fishes and aquatic invertebrates in Idaho streams. North American Journal of Fisheries Management 1:21-28.

Hall, D. N. 1988. Effects of eductor dredging of gold tailings on aquatic environments in Victoria. Proceedings of the Royal Society of Victoria 100:5359.

Harvey, B. C. 1986. Effects of suction gold dredging on fish and invertebrates in two California streams. North American Journal of Fisheries Management 6:401-409.

Holtby, L. B., and M. C. Healey. 1986. Selection for adult size in female coho salmon (Oncorhynchus kisutch). Canadian Journal of Fisheries and Aquatic Sciences 43:1946-1959.

Leopold, L. B., M. G. WoIman, and J. P. Miller. 1964. Fluvial processes in geomorphology. Freeman, San Francisco.

Montgomery, D. R., J. M. Buffington, N. P. Peterson, D. Schuett-Hames, and T. P. Quinn. 1996. Streambed scour, egg burial depths, and the influence of salmonid spawning on bed surface mobility and embryo survival. Canadian Journal of Fisheries and Aquatic Sciences 53:1061-1070.

Nawa, R. K., and C. A. Frissell. 1993. Measuring scour and fill of gravel streambeds with scour chains and sliding-bead monitors. North American Journal of Fisheries Management 13:634-639.

Thomas, V. G. 1985. Experimentally determined impacts of a small, suction gold dredge on a Montana stream. North American Journal of Fisheries Management 5:480-488.

van den Berghe, E. P., and M. R. Gross. 1984. Female size and nest depth in coho salmon (Oncorhynchus kisutch). Canadian Journal of Fisheries and Aquatic Sciences 41:204-206. 